\title{
Methylphenidate use and poly-substance use among undergraduate students attending a South African university
}

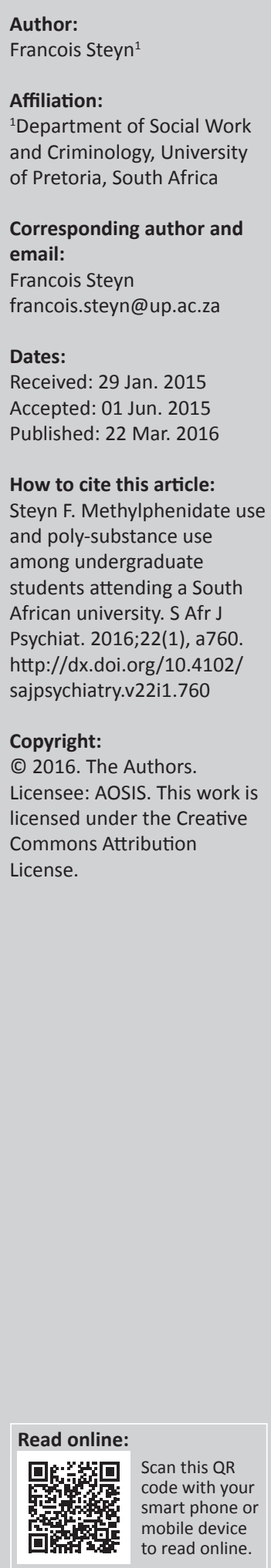

Background: Methylphenidate hydrochloride (MPH) is used in the treatment of attention deficit hyperactivity disorder (ADHD). The non-medical use of MPH by learners and students has been reported by numerous studies from abroad. The practice stems from beliefs about the benefits of MPH in achieving academic success. Little is known about the use of MPH in South African student populations.

Objectives: The study set out to determine (1) the extent and dynamics associated with MPH use and (2) poly-substance use among undergraduate students attending a South African university.

Methods: 818 students took part in a written, group-administered survey. Data analysis resulted in descriptive results regarding $\mathrm{MPH}$ use and tests of association identified differences in $\mathrm{MPH}$ and poly-substance use among respondents.

Results: One in six respondents (17.2\%) has used MPH in the past, although only $2.9 \%$ have been diagnosed with ADHD. Nearly a third (31.7\%) of users obtained MPH products illegally. The majority $(69.1 \%)$ used MPH only during periods of academic stress. A significant association $(p<0.001)$ was found between MPH use and the frequency of using alcohol, tobacco, cannabis, hard drugs (e.g. cocaine) and prescription medication.

Conclusion: MPH use among students appears similar to experiences abroad, especially in the absence of clinical diagnosis for ADHD. Institutions of higher education should inform parents and students about the health risks associated with the illicit use of MPH. Prescribers and dispensers of MPH products should pay close attention to practices of stockpiling medication and poly-substance use among students who use MPH.

\section{Introduction}

Methylphenidate hydrochloride (MPH) is used in the treatment of attention deficit hyperactivity disorder (ADHD). Prescriptions for and usage of MPH products have increased sharply since the early 1990s with accompanying concerns about potential misuse. ${ }^{1,2,3}$ While peer pressure and experimentation are important factors that contribute to substance use and misuse in young populations, students often experience strain to perform academically. Various strategies are followed to 'pull all-nighters' while studying for tests and exams, including the use of MPH to strengthen concentration and the ability to study for prolonged periods of time. ${ }^{3,4,5,6}$ However, evidence is inconclusive whether MPH lives up to the perception of the substance enhancing mental alertness and cognitive performance in persons not clinically diagnosed with ADHD. 2,7

Self-reported MPH use in student populations ranges from $5 \%$ to $34 \%, 5,8,9,10$ yet only $3 \%$ to $10 \%$ of MPH users have been diagnosed with ADHD.,3,10,11 Knowledge about the use of MPH as a study aid appears rife in universities, with up to $44 \%$ of students knowing a fellow student who uses MPH for academic reasons. ${ }^{10}$ Characteristics of students who are more likely to use MPH include being white, male, having attended a private school and students who present higher rates of using substances $3,5,6,11$ such as alcohol, tobacco (cigarettes), cannabis, cocaine, ecstasy and amphetamines. ${ }^{6}$

Students use MPH mainly to strengthen concentration, cognition, interest, attention, alertness, energy, focus and memory, to reduce fatigue, to improve academic performance and for recreational purposes. ${ }^{3,5,6,8,9,10,11}$ Very few students use MPH to socialise. ${ }^{5,11}$ Instead, it appears that $\mathrm{MPH}$ is used primarily in times of high academic stress (i.e. test weeks and exams) ${ }^{11}$ Procurement of MPH products is reportedly both easy and free from stigma. ${ }^{3,8}$ 
Students mostly take MPH orally with a small proportion taking MPH intra-nasally. ${ }^{3,10}$ Various side effects of MPH have been reported, including loss of appetite, difficulty sleeping, irritability and a depressed mood. ${ }^{5}$ Nonetheless, students who use $\mathrm{MPH}$ show little concern about using or misusing the substance $^{3}$ despite health-threatening consequences if usage is not professionally monitored. ${ }^{2}$

\section{Aim and methods}

The aim of the study was, firstly, to determine the use and dynamics associated with the use of $\mathrm{MPH}$ among undergraduate students attending a South African university and, secondly, to determine whether MPH users are more likely to use other substances compared to non-MPH users. Quantitative methods were employed to obtain data from 818 undergraduate students. A group-administered survey design was followed since this strategy ensures anonymity, which was imperative given that students were asked to respond to questions of (illegal) substance use. The survey took place over two days during the undergraduate classes of a discipline that attracts a large number of students annually. Questionnaires and letters of informed consent were distributed in class followed by an explanation of the purpose and procedures of the survey. Students were requested to complete the questionnaire in writing and to not discuss the questions or their answers with fellow students. Students were instructed to fold the completed one-page questionnaires twice so that others could not read their responses during collection.

The questionnaire designed by White et al. ${ }^{3}$ was adapted to reflect local terms (for example 'first year' instead of 'freshman') and to reduce the 10 open-ended questions to only one. In addition, questions were added about the frequency of students' use of alcohol, tobacco (cigarettes), cannabis, hard drugs (e.g. cocaine) and prescription medication. MPH use in this survey refers to 'have ever used' $\mathrm{MPH}$ products with follow-up questions regarding frequency and method of use, sourcing, side effects and openness of use.
The questionnaire was piloted with 50 students from other faculties, after which minor alterations were made. Data were captured manually in Microsoft Excel and exported to the Statistical Package for the Social Sciences (version 22). ${ }^{12}$ Inspection of the histograms with normality curves and tests of normality (Kolmogorov-Smirnov Z) revealed that the data were not normally distributed. The outcome thus necessitated the use of non-parametric tests to determine significant differences, in particular Pearson's chi-square and the MannWhitney $U$ test for which effect sizes $(r)$ were calculated. ${ }^{13}$

\section{Ethical considerations}

The survey adhered to the standard ethical considerations of anonymity, confidentiality and no harm. Respondents were provided with an information sheet which described the purpose and methods of the study, as well as the particulars of organisations that they could contact should they have concerns about their use of substances. Ethical clearance for the survey was obtained from the faculty's ethics committee and the registrar of the university.

\section{Results}

\section{Characteristics of the sample and methylphenidate use}

The mean age of respondents was 20.38 years $(\mathrm{SD}=2.19$ years). Female respondents constituted the bulk of the sample and the majority of respondents came from middle-income backgrounds (Table 1). Male and white respondents, as well as those from high-income backgrounds, appear more prone to using MPH. Population group $(r=-0.25)$ showed a stronger effect size for MPH use than gender $(r=-0.07)$ and economic background $(r=-0.08)$.

\section{Dynamics of methylphenidate use}

Nearly half of all respondents $(n=382 ; 46.8 \%)$ know of a fellow student who used MPH. One in six respondents $(n=141 ; 17.2 \%)$ has used MPH in the past, although only $2.9 \%(n=23)$ of all respondents has been diagnosed with ADHD. Nearly a third $(n=33 ; 31.7 \%)$ of MPH users do not

TABLE 1: Background characteristics of respondents and methylphenidate use.

\begin{tabular}{|c|c|c|c|c|c|c|c|c|}
\hline \multirow[t]{2}{*}{ Variable } & \multicolumn{2}{|c|}{ Total } & \multicolumn{2}{|c|}{ MPH used } & \multicolumn{2}{|c|}{ MPH not used } & \multirow[t]{2}{*}{$p$} & \multirow[t]{2}{*}{$r$} \\
\hline & $n$ & $\%$ & $n$ & $\%$ & $n$ & $\%$ & & \\
\hline \multicolumn{9}{|l|}{ Gender } \\
\hline Male & 185 & 22.7 & 42 & 22.7 & 143 & 77.3 & $<0.001$ & -0.07 \\
\hline Female & 630 & 77.3 & 99 & 15.7 & 531 & 84.3 & - & - \\
\hline \multicolumn{9}{|c|}{ Population group } \\
\hline Black & 244 & 29.8 & 9 & 3.7 & 235 & 96.3 & $<0.001$ & -0.25 \\
\hline Indian/Asian & 28 & 3.4 & 1 & 3.6 & 27 & 96.4 & - & - \\
\hline White & 499 & 60.9 & 124 & 24.8 & 375 & 75.2 & - & - \\
\hline \multicolumn{9}{|c|}{ Economic background } \\
\hline Low & 72 & 8.8 & 6 & 8.3 & 66 & 91.7 & 0.019 & -0.08 \\
\hline Middle & 616 & 75.6 & 107 & 17.4 & 509 & 82.6 & - & - \\
\hline High & 127 & 15.6 & 28 & 22.0 & 99 & 78.0 & - & - \\
\hline \multicolumn{9}{|c|}{ Type of school attended } \\
\hline Private & 247 & 30.3 & 51 & 20.6 & 196 & 79.4 & - & - \\
\hline
\end{tabular}

Source: Author's own work. 
have a prescription for the stimulant, with $27.3 \%(n=30)$ of users obtaining $\mathrm{MPH}$ products from a friend (at an average cost of R35.00 per tablet).

The greater proportion of MPH users started using the substance at university $(n=71 ; 68.3 \%)$ and the remainder commenced MPH use at school $(n=33 ; 31.7 \%)$. The majority of respondents $(n=65 ; 69.1 \%)$ reported using MPH only during tests and exams, with $17.0 \%(n=16)$ using MPH daily. A small proportion of respondents use MPH once or twice per week $(\mathrm{n}=3 ; 3.3 \%)$, three to four times per week $(n=5$; $5.4 \%)$ and once or twice per month $(n=5 ; 5.4 \%)$. The larger part of MPH users indicated that it is very easy $(n=47$; $41.2 \%)$, somewhat easy $(n=27 ; 23.7 \%)$ and neither easy nor difficult ( $n=25 ; 21.9 \%)$ to obtain MPH products. Nine users (7.9\%) noted it somewhat difficult and six (5.3\%) stated that it is very difficult to obtain $\mathrm{MPH}$ products. More than half of users $(n=62 ; 58.5 \%)$ indicated that they are open about using MPH, $35.8 \%(n=38)$ stated that only those close to them know and six (5.6\%) noted that they keep it a secret.

Only one respondent $(0.9 \%)$ takes $\mathrm{MPH}$ intra-nasally with the vast majority taking the stimulant orally $(n=106 ; 99.1 \%)$. The reasons for using MPH were to enhance concentration (41.7\%), to improve study habits $(26.4 \%)$, to reduce hyperactivity $(10.2 \%)$, to achieve higher marks $(19.1 \%)$ and for socialising (2.1\%). MPH users experienced a variety of side effects of which the five most often cited were insomnia $(n=13 ; 17.3 \%)$, moodiness $(n=11 ; 14.7 \%)$, loss of appetite $(n=9 ; 12.0 \%)$, dry mouth $(n=6 ; 8.0 \%)$ and anxiety $(n=5 ; 6.7 \%)$.

\section{Methylphenidate and use of other substances}

Although a significant association featured for the co-use of MPH and other substances, tobacco $(r=0.24)$ and cannabis $(r=0.21)$ presented the strongest effect sizes of poly-substance use (Table 2).

Table 3 cross-tabulates the results of MPH users and nonusers with the self-reported frequency of using other substances. MPH users surpassed non-MPH users in the use of other substances in the 'often' and 'sometimes' categories.
TABLE 2: Methylphenidate and use of other substances.

\begin{tabular}{|c|c|c|c|c|c|c|}
\hline \multirow[t]{2}{*}{ Variable } & \multicolumn{2}{|c|}{ MPH used } & \multicolumn{2}{|c|}{ MPH not used } & \multirow[t]{2}{*}{$p$} & \multirow[t]{2}{*}{$r$} \\
\hline & $n$ & $\%$ & $n$ & $\%$ & & \\
\hline Alcohol & 120 & 88.8 & 526 & 79.1 & 0.008 & 0.09 \\
\hline Tobacco & 67 & 52.3 & 147 & 22.8 & $<0.001$ & 0.24 \\
\hline Cannabis & 57 & 44.5 & 127 & 19.7 & $<0.001$ & 0.21 \\
\hline Hard drugs (e.g. cocaine) & 7 & 5.7 & 5 & 0.8 & $<0.001$ & 0.14 \\
\hline Prescription medication & 114 & 85.1 & 455 & 70.0 & $<0.001$ & 0.12 \\
\hline
\end{tabular}

Source: Author's own work.

\section{Discussion}

Results from the present survey are similar to findings from abroad regarding the self-reported use of $\mathrm{MPH}$ among students $(17.2 \%)^{3,10}$ and the finding that a small proportion of MPH users has been diagnosed with ADHD $(2.7 \%) .^{3,10,11}$ In the same way, the reasons why students use $\mathrm{MPH}$ (mostly to enhance academic performance) and the side effects they experience (notably sleeping disturbances, loss of appetite and moodiness) correspond with existing evidence. ${ }^{3,5,6,8,9,10,11}$ Furthermore, the results show that MPH users are more prone to using other substances, ${ }^{6}$ although $\mathrm{MPH}$ poly-use with tobacco and cannabis appears more pronounced. The study further supports findings that white students and those from higher-income backgrounds are associated with higher levels of MPH use, ${ }^{5,6,11}$ possibly due to this profile in South Africa generally having better access to private medical aid and accompanying specialised health care.

Similar to the available evidence, students do not appear to use $\mathrm{MPH}$ for socialising purposes but primarily during periods of academic stress. ${ }^{5,11}$ Nearly a third of users did not have a prescription for MPH, thus indicating that they obtain products illegally. These findings raise concerns that students with $\mathrm{MPH}$ prescriptions may stockpile their medication over time in order to share it with or to sell it to fellow students. As elsewhere, the results confirm that local MPH users are relatively open about using the substance and that it is relatively easy to obtain $\mathrm{MPH}$ products, ${ }^{3,8}$ whether via licit or illicit channels. With nearly half of respondents in the present survey knowing of a fellow student who uses MPH and the

TABLE 3: Methylphenidate use and frequency of use of other substances.

\begin{tabular}{|c|c|c|c|c|c|c|c|c|c|c|}
\hline \multirow[t]{2}{*}{ Variable } & \multicolumn{2}{|c|}{ Alcohol } & \multicolumn{2}{|c|}{ Tobacco } & \multicolumn{2}{|c|}{ Cannabis } & \multicolumn{2}{|c|}{ Hard drugs (e.g. cocaine) } & \multicolumn{2}{|c|}{ Prescription medication } \\
\hline & $n$ & $\%$ & $n$ & $\%$ & $n$ & $\%$ & $n$ & $\%$ & $n$ & $\%$ \\
\hline \multicolumn{11}{|l|}{ Often: } \\
\hline Used & 43 & 31.9 & 33 & 25.8 & 16 & 12.5 & 1 & 0.8 & 35 & 26.1 \\
\hline Not used & 105 & 15.8 & 55 & 8.5 & 13 & 2.0 & 0 & 0.0 & 103 & 15.8 \\
\hline \multicolumn{11}{|c|}{ Sometimes: } \\
\hline Used & 49 & 36.3 & 14 & 10.9 & 11 & 8.6 & 3 & 2.4 & 36 & 26.9 \\
\hline Not used & 219 & 32.9 & 35 & 5.4 & 24 & 3.7 & 1 & 0.2 & 125 & 19.2 \\
\hline \multicolumn{11}{|l|}{ Seldom: } \\
\hline Used & 28 & 20.7 & 20 & 15.6 & 30 & 23.4 & 3 & 2.4 & 43 & 32.1 \\
\hline Not used & 202 & 30.4 & 57 & 8.8 & 87 & 13.5 & 4 & 0.6 & 227 & 34.9 \\
\hline \multicolumn{11}{|l|}{ Never: } \\
\hline Used & 15 & 11.1 & 61 & 47.7 & 71 & 55.5 & 116 & 94.3 & 20 & 14.9 \\
\hline Not used & 139 & 20.9 & 499 & 77.2 & 519 & 80.7 & 633 & 98.2 & 195 & 30.0 \\
\hline$p$ & \multicolumn{2}{|c|}{$<0.001$} & \multicolumn{2}{|c|}{$<0.001$} & \multicolumn{2}{|c|}{$<0.001$} & \multicolumn{2}{|c|}{$<0.001$} & \multicolumn{2}{|c|}{$<0.001$} \\
\hline
\end{tabular}

Source: Author's own work. 
majority of users having commenced MPH use at university, it is clear that some form of awareness exists and may be perpetuated on campus about the perceived benefits of $\mathrm{MPH}$ as a study aid.

\section{Recommendations}

University management and student support services should create awareness among parents and students about the health risks associated with the misuse of MPH products. Steps should be taken to prevent students with $\mathrm{MPH}$ prescriptions from sharing their medication with fellow students. ${ }^{3}$ Medical practitioners and pharmacists should take note of the misuse of $\mathrm{MPH}$ among students and carefully follow relevant diagnosis and monitoring protocols in the prescription and dispensing of MPH products, even more so in light of irregular use, sharing and selling of medication and poly-substance use.

\section{Limitations and future research}

The study relied on non-probability sampling procedures and, despite the large number of respondents, generalisation to other settings and populations should be done with caution. Matters of representation are further confounded by not all students attending class, attrition and the bulk of respondents stemming from one specific faculty. Regardless of assurances of anonymity, the study depended on measures of self-report, which is known for under-reporting in matters such as substance use.

Future research, with random and stratified sampling procedures, should focus on MPH use across academic faculties and institutions of higher education. The views of stakeholders, in particular medical practitioners and pharmacists, should be determined regarding the use of $\mathrm{MPH}$ among student populations. In addition, a more definite profile of the users of MPH products should be developed in order to identify risk populations and appropriate interventions.

\section{Acknowledgements}

Gratitude is extended to the postgraduate students who assisted with the electronic capturing of the data.

\section{Competing interests}

The author declares that he has no financial or personal relationships that may have inappropriately influenced him in writing this article.

\section{References}

1. Bogle KE, Smith BH. Illicit methylphenidate use: A review of prevalence, availability, pharmacology, and consequences. Curr Drug Abuse Rev 2009;2(2):157-176. PMID: 19630746

2. Verster C, Van Niekerk AA. Moral perspectives on stimulant use by healthy students. S Afr Med J 2012;102(12):909-911. http://dx.doi.org/10.7196/ SAMJ.6090

3. White BP, Becker-Blease KA, Grace-Bishop K. Stimulant medication use, misuse and abuse in an undergraduate and graduate sample. J Am Coll Health 2006;54(5):261-268. http://dx.doi.org/10.3200/JACH.54.5.261-268

4. Babcock $Q$, Byrne T. Student perceptions of methylphenidate abuse at a public liberal arts college. J Am Coll Health 2000;49(3):143-145. http://dx.doi. org/10.1080/07448480009596296

5. Rabiner DL, Anastopoulos AD, Costello EJ, Hoyle RH, Swartzwelder HS. Motives and perceived consequences of nonmedical ADHD medication use by college students. Are students treating themselves for attention problems? J Atten Disord 2009;13(3):259-270. http://dx.doi.org/10.1177/1087054708320399

6. Teter CJ, McCabe SE, Cranford JA, Boyd CJ, Guthrie SK. Prevalence and motives for illicit use of prescription stimulants in an undergraduate student sample. J Am Coll Health 2010;53(6):253-262. http://dx.doi.org/10.3200/JACH.53.6. 253-262

7. Mommaerts J, Beerens $G$, Van den Block L, et al. Influence of methylphenidate treatment assumptions on cognitive function in healthy young adults in a doubleblind, placebo-controlled trial. Psychol Res Behav Manag 2013;6:65-74. http:// dx.doi.org/10.2147/PRBM.S47526

8. DeSantis AD, Webb EM, Noar SM. Illicit use of prescription ADHD medications on a college campus: a multimethodological approach. J Am Coll Health 2008;7(3):315-324. http://dx.doi.org/10.3200/JACH.57.3.315-324

9. DuPaul GJ, Weyandt LL, O'Dell SM, Varejao M. College students with ADHD. Current status and future directions. J Atten Disord 2009;13(3):234-250. http:// dx.doi.org/10.1177/1087054709340650

10. Hall KM, Irwin MM, Bowman KA, Frankenberger W, Jewett DC. Illicit use of prescribed stimulant medication among college students. J Am Coll Health 2005;53(4):167-174. http://dx.doi.org/10.3200/JACH.53.4.167-174

11. Advokat CD, Guidry D, Martino L. Licit and illicit use of medications for attentiondeficit hyperactivity disorder in undergraduate college students. J Am Coll Health 2008;56(6):601-606. http://dx.doi.org/10.3200/JACH.56.6.601-606

12. IBM SPSS Statistics for Windows [computer software]. Version 22.0. Armonk, NY: IBM Corp. 2014.

13. Field A. Discovering statistics using SPSS. Los Angeles: SAGE; 2009: p. 550. 